\title{
Detection of Ru potential metallodrug in human urine by MALDI-TOF mass spectrometry: Validation and options to enhance the sensitivity
}

\author{
Nádia Nunes $^{\mathrm{a}}$, Iva Popović ${ }^{\mathrm{b}}$, Elder Abreu ${ }^{\mathrm{a}}$, Dina Maciel ${ }^{\mathrm{a}}$, João Rodrigues ${ }^{\mathrm{a}, \mathrm{c}}$, Juan Soto ${ }^{\mathrm{d}}$, \\ Manuel Algarra ${ }^{\mathrm{e}, *}$, Marijana Petković ${ }^{\mathrm{a}, * *}$ \\ ${ }^{a}$ CQM-Centro de Química da Madeira, Universidade da Madeira, Campus da Penteada, 9020-105, Funchal, Portugal \\ ${ }^{\mathrm{b}}$ Department of Atomic Physics, VINČA Institute of Nuclear Sciences, University of Belgrade, Belgrade, Serbia \\ ${ }^{\mathrm{c}}$ School of Materials Science and Engineering, Center for Nano Energy Materials, Northwestern Polytechnical University, Xi'an, 710072, China \\ d Department of Physical Chemistry, Faculty of Science, University of Málaga, Campus de Teatinos s/n, 29071, Malaga, Spain \\ e Department of Inorganic Chemistry, Faculty of Science, University of Málaga, Campus de Teatinos s/n, 29071, Malaga, Spain
}

\section{A R T I C L E I N F O}

\section{Keywords:}

$\mathrm{RuCp}$

Metallodrugs

Carbon dots

MALDI-TOF MS

Urine

DFT calculations

\begin{abstract}
A B S T R A C T
We studied the possibility of detection of $\left[\mathrm{Ru}\left(\eta^{5}-\mathrm{C}_{5} \mathrm{H}_{5}\right)\left(\mathrm{PPh}_{3}\right)_{2} \mathrm{Cl}\right]$ (abbreviated by RuCp) complex as a model system for Ru-based metallodrugs in human urine by using matrix-assisted laser desorption/ionization time-offlight mass spectrometry (MALDI-TOF MS) without previous purification or removal of inorganic salts. Inorganic salts might prevent the detection of RuCp by MALDI-TOF MS, most likely through the increased number and intensity of background/organic matrix signals. This problem might be overcome by the acquisition of matrixfree spectra and the addition of nanoparticles, such as carbon dots, to the urine solution. Our results suggest that RuCp is easily detectable by MALDI-TOF MS in all acquisition conditions, with the CHCA matrix being the best for acquisition in phosphate-containing solutions, whereas in urine, DHB and matrix-free approach demonstrated the highest sensitivity, precision, and reproducibility. The sensitivity of matrix-free MALDI detection of RuCp could be increased by the addition of carbon dots to the urine. Based on theoretical calculations for all matrix/analyte combinations, the model for the interaction of RuCp with carbon dots was established, and higher sensitivity explained.
\end{abstract}

\section{Introduction}

Detection of small molecules, such as metabolites and drugs, in biological fluids, such as urine, is of high importance, especially in clinical. The presence of specific metabolites in urine is a diagnostic marker for kidney failure, diabetes, specific nephrotoxic agents, and other diseases [1,2]. Apart from these standard biochemical analyses, in a drug discovery studies, evaluation of excretion of a small molecule is an integral part, so-called ADME "package" (Absorption, Distribution, Metabolism, and Excretion) [3]. Information about the kinetics of excretion of certain drugs and their metabolites can point to the data about the therapy, optimum dose, and the pharmacokinetics of a drug.

Ruthenium-based chemotherapeutics are beyond the cis-diamminedichloroplatinum (II) (cisplatin, cisPt), which is successfully used in the anti-tumour therapy over decades, but that is known to induce severe side effects $[4,5]$. New complexes have desired properties in terms of somewhat higher selectivity towards tumour tissues compared to healthy ones [6-8], but also the activity against the metastases, such as NAMI-A and KP1019 [9,10]. These two compounds failed in the advanced stages of clinical trials, once do not entirely satisfy the criteria for mass drug administration and human use [11,12]. In addition to the development and studies of new Ru-compounds (II and III), there are also increasing efforts of scientists towards new approaches. For instance, by increasing the efficiency of the drugs and their selectivity, and expand water solubility, as it was described recently by Riccardi and co-workers [13]. Among them, there are several iminophosphorane Ru (II) complexes, that were proven to be more cytotoxic than cisPt, which exhibited higher uptake by cancer cells compared to the healthy tissues, such as kidney and liver, as demonstrated on an animal tumour model system [14]. In addition, there is evidence that chemotherapeutics based on Pt- and Ru-complexes can be nephrotoxic agents and that they increase the level of proteins in urine [15].

\footnotetext{
* Corresponding author.

$* *$ Corresponding author.

E-mail addresses: malgarra67@gmail.com (M. Algarra), petkovic.marijana.71@gmail.com (M. Petković).
} 
The facts mentioned above emphasize the importance of carefully conducted toxicity studies, as well as further in vivo screenings, which can be done, either in patients treated with increasing concentrations of chemotherapeutics [16] or in models that mimic human tumour pathology [17]. However, the improvement of non-invasive methods for their detection and the metabolite characterization in biological fluids is an essential and challenging hot topic [18].

Methods that can be used in the detection and quantification of metallodrugs, such as Ru-compounds in urine and other biological fluids, often require pre-separation by liquid chromatography with mass spectrometric detection, such as inductively coupled plasma mass spectrometry (ICP MS) [19], radioactive [3] or fluorescence labelling [18]. Concerning the speed of sample preparation and analyses, matrix-assisted desorption/ionization time-of-flight mass spectrometry (MALDI-TOF MS) offers alternatives to other approaches, which involve the derivatization of samples and further purification of biological matrix [20]. For MALDI methodology, no derivatization and no tedious sample preparation procedure is required, and the detectability of $\mathrm{Ru}, \mathrm{Pt}$ and Pd-complexes has already been demonstrated [21,22]. On the other hand, the presence of high concentrations of inorganic ions in biological samples can interfere with the signals and can even decrease the sensitivity of their detection. The addition of nanoparticles can help in overcoming this effect [23].

Gouveia and co-workers [24] showed that chloro ( $\eta^{5}$-cyclopentadienyl)bis(triphenylphosphine) ruthenium(II) - $\left[\mathrm{Ru}\left(\eta^{5}-\mathrm{C}_{5} \mathrm{H}_{5}\right)\right.$ $\left(\mathrm{PPh}_{3}\right)_{2} \mathrm{Cl}$ ] (RuCp) - demonstrate remarkable toxicity against a set of cancer cells. Including cisPt-resistant human ovarian carcinoma cells and human mesenchymal stem cells that are often found in the tumour microenvironment, where they seem to play a role in tumor progression and drug resistance [25].

In this work, we have studied the potential for the detection of $\mathrm{RuCp}$ in human urine as the model system for the detection of metallodrugs and their metabolites excreted during anticancer therapy. In addition to the method validation, a theoretical model for the interaction between matrices and the analyte was established. Results demonstrate high potential for the application of detection of Ru-based metallodrugs in biological fluids by applying MALDI-TOF MS, which can be even amplified by the addition of carbon-based nanoparticles (carbon dots, CDs), as auxiliary agents.

\section{Experimental}

\subsection{Chemicals preparation}

Chloro(cyclopentadienyl)bis(triphenylphosphine)ruthenium(II) was synthesized, adapting a procedure previously reported [26], according to the scheme presented in Fig. S1A. Briefly, ruthenium (III) chloride hydrate $\left(\mathrm{RuCl}_{3} \cdot x \mathrm{H}_{2} \mathrm{O}\right)$, triphenylphosphine $\left(\mathrm{PPh}_{3}\right)$ and freshly distilled cyclopentadiene $(\mathrm{Cp})$ were mixed in degassed ethanol (EtOH), under $\mathrm{N}_{2}$ atmosphere and left at reflux temperatures for $2 \mathrm{~h}$. RuCp was properly purified and characterized by ${ }^{1} \mathrm{H}$ and ${ }^{31} \mathrm{P}$ NMR, FTIR, and LC-MS/MS $\left(\mathrm{ESI}^{+}\right.$) (Figs. S1B, C, D and, E respectively). Matrices for MALDI-TOF MS, 2,5-dihydroxybenzoic acid (DHB), and $\alpha$-cyano-hydroxycinnamic acid (CHCA) were purchased from Sigma Aldrich (Germany) and used as supplied. Carbon dots were synthesized from lactose, as previously described [27]. Solvent for organic matrices was TA30, the composition of which is $0.05 \%$ trifluoroacetic acid, and $30 \%$ acetonitrile in water. Phosphate buffered saline salt solution (PBS) was $10 \mathrm{mM}$ concentration with $137 \mathrm{mM} \mathrm{NaCl}$ and $2.7 \mathrm{mM} \mathrm{KCl}, \mathrm{pH} 7.4$. Urine was collected from an individual (healthy donor) and used undiluted for MALDI-TOF MS. All reagents were supplied from Sigma Aldrich, Germany, and used without further purification.

\subsection{Sample preparation for MALDI-TOF MS}

MALDI-TOF MS was performed on the Autoflex Max Device (Bruker,
Bremen, Germany), equipped with the SmartBeam ${ }^{\mathrm{TM}}$ laser emitting at $355 \mathrm{~nm}$. The maximum laser frequency was $2 \mathrm{kHz}$, and all spectra were acquired in a low mass range $<1000$ without deflection, using a reflector detector (detector voltage 1789) with a 10 bit digitizer, and by applying the delayed extraction time $(120 \mathrm{~ns})$. The method and spectra were calibrated using the position of signals arising from matrices (DHB and CHCA) as internal calibrants in the required mass range, in the spectra acquired with corresponding matrices, whereas in the case of the matrixfree acquisition, the position of signals arising from DHB were used as external calibrants. RuCp was dissolved in TA30 first and diluted in PBS or urine at various concentrations and mixed in a 1:1 vol ratio with matrix solutions. After that, $0.5 \mu \mathrm{L}$ of the mixture was applied on the sample plate and left at room temperature to crystallize. Separately, various concentrations of RuCp in PBS/urine or with the addition of CDs $(1 \mathrm{mg} / \mathrm{mL}$ ) were applied to the MALDI target. For validation of the method, the samples were applied in quadruplicate, and spectra acquired during three consecutive days.

Acquired spectra were processed by using the Flex Analysis 3.4 licenced software (Bruker) and the detection limit of signals was set at the value 5 as minimum. Calibration was performed as described above.

\subsection{Statistical analysis}

The surface of each spot in a quadruplicate was shot randomly with 2000 individual laser shots, and the mean value of signal-to-noise ratios $(\mathrm{S} / \mathrm{N})$ from the highest signal in the group from Ru-containing ions, as well as the peak area (PA) from all isotopes, were calculated. Obtained results were analysed statistically by one-way ANOVA. Relative standard deviations from $\mathrm{S} / \mathrm{N}$ ratios from quadruplicates were calculated, and they represent the measure of the sample homogeneity/shot-to-shot reproducibility. For the calculation of a day-to-day precision, the same procedure was applied for three consecutive days. The overview of the results is presented by the "box and whisker" plots for a selected concentration, in which the "box" contains the middle half of the S/N and PA data points. The variability outside the upper and lower quartiles is indicated by the lines that extend from the boxes (whiskers). This presentation is useful for comparison of the detectability and precision of measurements concerning the goal that must be achieved.

\subsection{Computational details}

The quantum chemical calculations (ionization potential, vertical excitation energies, minimum geometry optimizations, and frequencies) have been performed by applying density functional theory (DFT) with the hybrid exchange-correlation functional M05-2X [28] corrected by Grimme's empirical dispersion (D3 version) $[29,30]$ and in conjunction with the def2-SVPP basis sets on all the atoms [31,32], as implemented in GAUSSIAN16 [33]. To calculate adsorption energies, we have used standard expressions of Statistical Thermodynamics with programs implemented previously by one of us [34].

\section{Results and discussion}

\subsection{MALDI-TOF mass spectrometry of RuCp in PBS and urine}

Since RuCp absorbs in the UV range, it is also possible that it can be detected without a matrix, in a so-called, LDI mode, but the presence of inorganic salts in biological fluids (urine) might increase the limit of detection of this compound. Therefore, all measurements were done in parallel in PBS to explore further the possibility of using the MALDI MS approach for the detection of various compounds in other biologicals fluids.

The spectra presented in Figs. 1A-2A confirm the detectability of RuCp in LDI mode in PBS and urine, respectively, without any further purification. Detectable Ru-containing ions are generated by losing $\mathrm{Cl}^{-}$ anion and simultaneously $\mathrm{Cl}^{-}$and $\mathrm{PPh}_{3}$ ligand at $\mathrm{m} / z$ 691.2 and 429.1, 

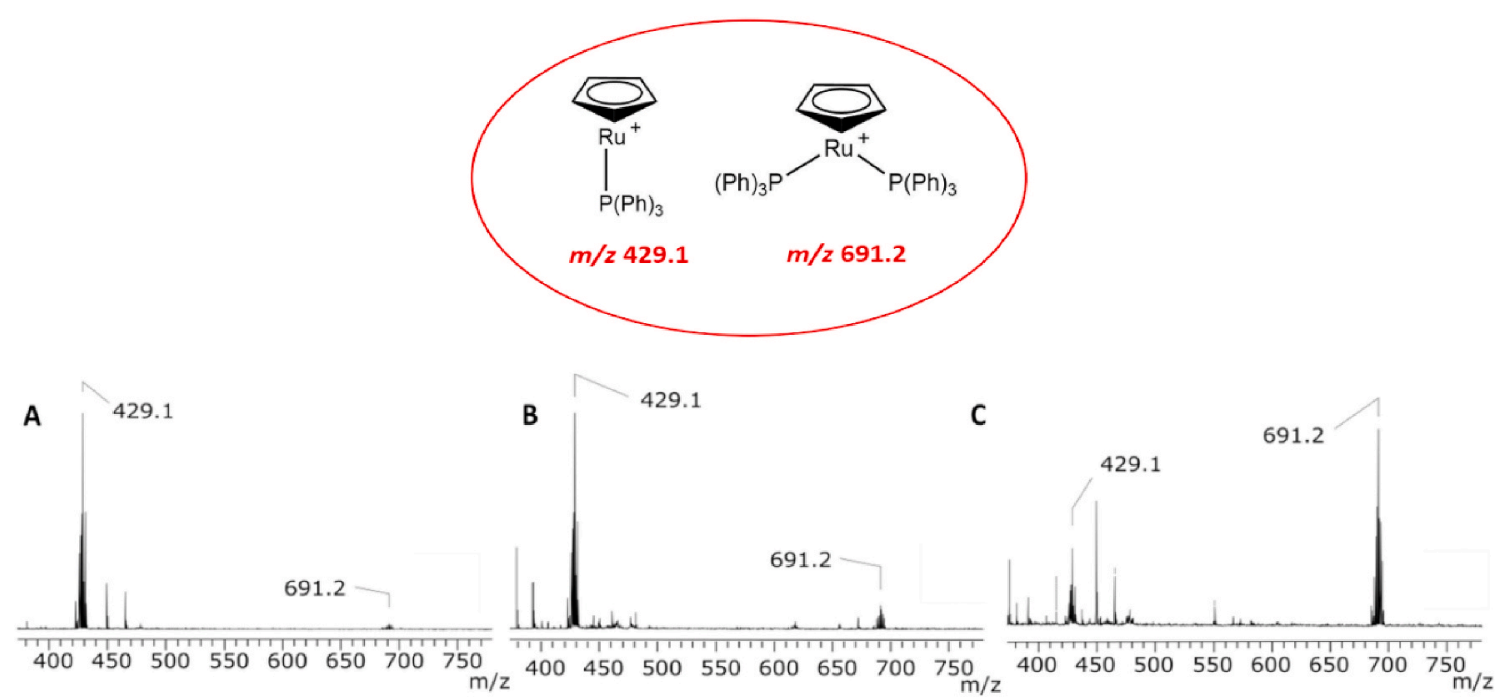

Fig. 1. Chemical structure of the positive ion MALDI-TOF mass spectra of RuCp acquired (A) without matrix, (B) with CHCA, and (C) DHB in PBS.

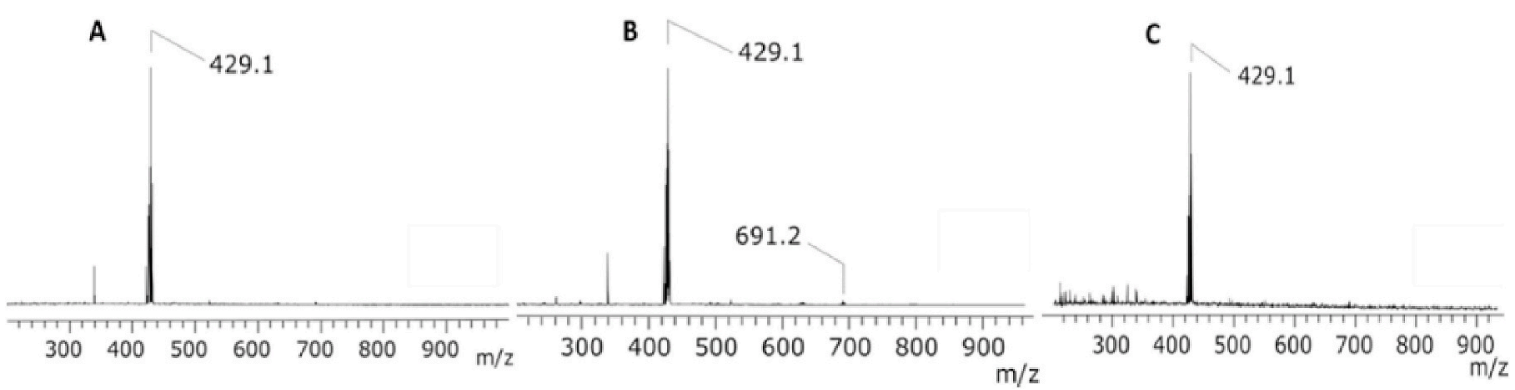

Fig. 2. Positive ion MALDI-TOF MS of RuCp acquired (A) without a matrix, (B) with CHCA, and (C) DHB in urine.

respectively. The spectra of RuCp in PBS acquired with organic matrices, CHCA and DHB, are given in Fig. 1B-C, respectively, whereas in Fig. $2 \mathrm{~B}-\mathrm{C}$ is represented the spectra in urine acquired with the same matrices. It is evident that the signal at $m / z 691.2$ is of higher intensity if spectra are acquired with DHB (in PBS as a solution, Fig. 1C), compared to the signal at $m / z$ 429.1. On the other hand, this signal was almost no detectable in urine, and spectra are dominated by the signal at $m / z$ 429.1 (Fig. 2B-C).

It is well known that the homogeneity of the distribution of the matrix/analyte co-crystals determines the potential for quantification and accuracy of the measurement. To check this, we have determined relative standard deviations from three samples (triplicates) and presented in Fig. 3 together with camera images from the samples applied under various conditions. MALDI is known for low shot-to-shot reproducibility caused by inhomogeneous co-crystallization of analytes with matrix, and it is usually considered that the RSD up to $20 \%$ is acceptable in terms of analyte quantification [35].

The best homogeneity was achieved when urine spiked with RuCp was mixed with DHB, but this value was higher than $20 \%$. It is clear that none of the methods satisfy the required parameter, but other criteria that determine the suitability of the approach for the detection and potential quantification of RuCp in urine, such as sensitivity, within-day and day-to-day precision, and reproducibility, respectively; these are studied and described further in text.

Since $\mathrm{Ru}$ is composed of 7 stable isotopes, and in combination with isotopes of other elements in the molecule, this can complicate the
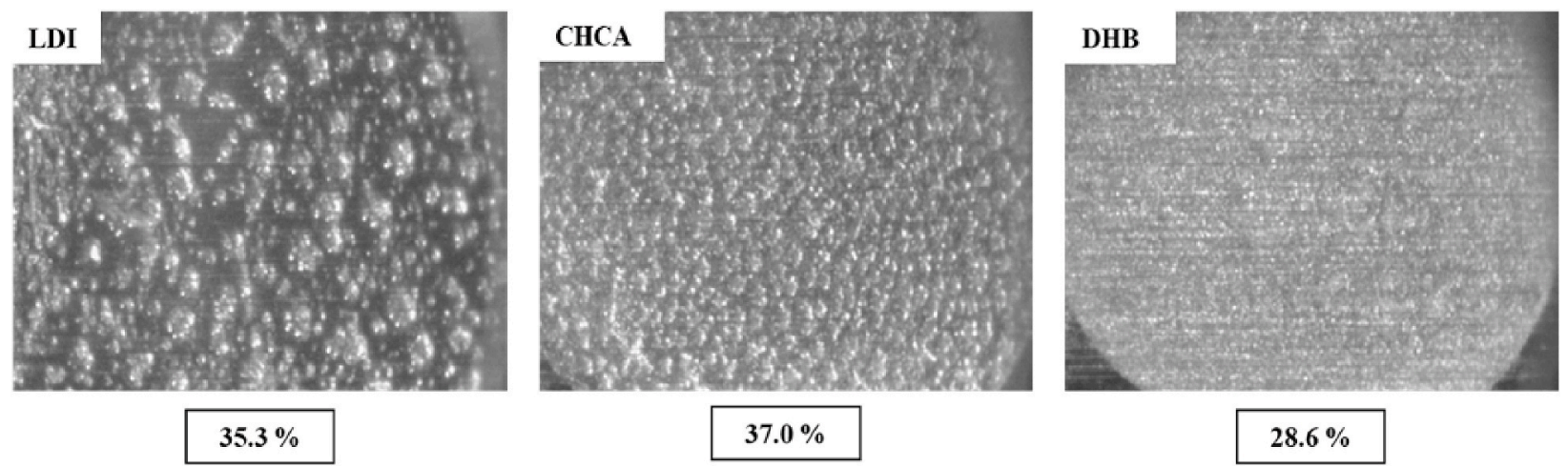

Fig. 3. Camera images of the spots on MALDI target with dried mixtures of urine spiked with RuCp without matrix, with CHCA, or DHB. The relative standard deviations are indicated in the corresponding figures. 
spectra, on the one hand, and the other, it makes the identification of Rucontaining signals easier. Fig. 4 showed the complexity of the signals arising from RuCp-derived ions detected at $m / z 429.1$ (Fig. 4A) and detected at $m / z 691.2$ (Fig. 4B). The theoretical isotopic pattern of these two signals is given in Fig. S2.

For the simplicity of presentation, only the most intense signals in a group are indicated in experimental spectra and their $\mathrm{S} / \mathrm{N}$ values compared between different procedures. In the case that peak area was calculated, the sum of peak area corresponding to individual isotope combination was considered: for the signal at $m / z 429.1$, the range $m / z$ $423.1-434.2$ was analysed, and in the case of the signal at $m / z 691.2$ the range $m / z$ 685.2-695.2 was considered.

\subsection{Detectability of RuCp in PBS and urine}

Limit of detection (LOD) is calculated taking S/N 3 as the limit of detection, and the peak area is assessed only in those spectra, in which all corresponding signals are detectable. In PBS, the lowest concentration of RuCp (Table 1, and Table S1) was detectable with DHB as matrix $(11.34 \mu \mathrm{g} / \mu \mathrm{L})$, whereas slightly higher LOD was detectable under LDI conditions $(14.74 \mu \mathrm{g} / \mu \mathrm{L})$, according to $\mathrm{S} / \mathrm{N}$ ratio for the signal at $\mathrm{m} / \mathrm{z}$ 429.1. A similar concentration $(13.13 \mu \mathrm{g} / \mu \mathrm{L})$ was calculated for the signal at $m / z 691.2$ based on S/N values with CHCA as matrix. In urine, the lowest concentration was detectable without matrix, i.e., in the LDI mode, whereas the signal corresponding to the ion at $m / z 429.1$ was detectable at all concentrations with DHB matrix. On the other hand, the signal generated by the loss of $\mathrm{Cl}^{-}\left([\mathrm{M}-\mathrm{Cl}]^{+}\right)$mostly was not detectable. The reason why mostly the signal at lower $m / z$ was detectable in the spectra, and not both signals, could be different, such as better detectability of smaller ions, but also, better stability of the ion at $\mathrm{m} / \mathrm{z}$ 429.1 in the presence of high content of inorganic salts. Furthermore, the $[\mathrm{M}-\mathrm{Cl}]^{+}$might be reactive, and the free position on the ruthenium sphere probably is occupied with another ligand or solvent molecule. These species are not detected.

The precision of the method was determined by comparison of the within-day precision and day-to-day reproducibility during three days of the spectra acquisition. Determination of the accuracy gave us insights into the method's reliability. It enabled the estimation if the method is suitable to be used for a potential routine quantitative application, e.g., in a clinical laboratory, but also for the analysis of the potential metabolites of metallodrugs. To test the method accuracy and the method reproducibility, we have performed a one-way ANOVA test, and the F parameters (both determined $\mathrm{F}$ and $\mathrm{F}_{\text {crit }}$ ) for one of the tested concentrations under different conditions are listed in Table 2, whereas the values obtained for two other concentrations $(0.625 \mu \mathrm{M}$ and $624.8 \mu \mathrm{M})$ are given in Table S2. Basically, if the F parameter is higher than $\mathrm{F}_{\text {crit }}$
Table 1

LODs $(\mu \mathrm{g} / \mathrm{mL})$ for both signals arising from RuCp detected in the positive ion mode MALDI-TOF mass spectra under different conditions. The corresponding linearity equations are given in Table $\mathrm{S} 1$.

\begin{tabular}{lllll}
\hline Matrix & $\begin{array}{l}\text { S/N/Peak Area } \\
(429.1) \text { in PBS }\end{array}$ & $\begin{array}{l}\text { S/N/Peak Area } \\
(429.1) \text { in } \\
\text { Urine }\end{array}$ & $\begin{array}{l}\text { S/N/Peak Area } \\
(691.2) \text { in PBS }\end{array}$ & $\begin{array}{l}\text { S/N/Peak Area } \\
(691.2) \text { in } \\
\text { Urine }\end{array}$ \\
\hline CHCA & $18.36 / 15.32$ & $128.10 / 175.1$ & $13.13 / 15.98$ & $317.50 / 401.4$ \\
DHB & $11.34 / 16.44$ & $177.98 / 96.26$ & $21.45 / 14.05$ & nd \\
LDI & $14.74 / 11.72$ & $111.90 / 150.48$ & Nd & nd \\
\hline
\end{tabular}

value than the day-to-day repeatability is higher than the within-day precision. $\mathrm{F}_{\text {crit }}$ value is determined from the statistical tables, which represent the upper critical values of the F distribution for the one-way ANOVA with the precision degree of $95 \%$ and the factor $\alpha$ of 0.05 for four measurements. Within-day precision and day-to-day repeatability represent the variability in the $\mathrm{S} / \mathrm{N}$ values and peak area of the $\mathrm{Ru}$ containing signal, determined from each applied spot on the MALDI plate. In the case of LDI analysis of RuCp in urine, at the presented concentration, as well as for the lowest concentration in PBS (Table S2) day-to-day repeatability was better than the within-day precision, whereas, in urine, CHCA gave somewhat better day-to-day reproducibility (Table 2, Table S2). Similar was also obtained for higher RuCp concentration analysed $(624.8 \mu \mathrm{M})$, in which CHCA gave also better dayto day reproducibility than the within-day precision. It should be emphasized that not all signals are detectable under all acquisition conditions and at all tested concentrations, as it is presented in Table 1.

The acceptable values of variations in terms of analyte quantification

Table 2

$\mathrm{F}$ and $\mathrm{F}_{\text {crit }}$ values for the signal parameters detected in the RuCp spectra acquired under different acquisition conditions. The concentration at which the ANOVA test is presented was $78.125 \mu \mathrm{M}$. The cases where $\mathrm{F}<\mathrm{F}_{\text {crit }}$ are indicated by an asterisk.

\begin{tabular}{llllll}
\hline Parameter/Matrix & $m / z$ & \multicolumn{4}{l}{ CHCA DHB LDI } \\
\hline S/N in PBS & 429.1 & $\mathrm{~F}$ & 30.93 & 29.74 & $1.50^{*}$ \\
& & $\mathrm{~F}_{\text {crit }}$ & 4.46 & 4.26 & 4.26 \\
Peak area in PBS & 429.1 & $\mathrm{~F}$ & 15.82 & 21.28 & $0.39^{*}$ \\
& & $\mathrm{~F}_{\text {crit }}$ & 4.46 & 4.46 & 4.26 \\
S/N in PBS & 691.2 & $\mathrm{~F}$ & 20.38 & 10.15 & $2.24^{*}$ \\
& & $\mathrm{~F}_{\text {crit }}$ & 4.26 & 4.26 & 5.14 \\
Peak area in PBS & \multirow{2}{*}{691.2} & $\mathrm{~F}$ & 13.67 & 10.33 & $1.84^{*}$ \\
& & $\mathrm{~F}_{\text {crit }}$ & 4.26 & 4.26 & 5.79 \\
S/N in urine & 429.1 & $\mathrm{~F}$ & $2.66^{*}$ & 10.22 & 200.79 \\
& & $\mathrm{~F}_{\text {crit }}$ & 4.46 & 6.61 & 4.74 \\
Peak area in urine & 429.1 & $\mathrm{~F}$ & $3.06^{*}$ & 11.13 & 44.46 \\
& & $\mathrm{~F}_{\text {crit }}$ & 4.26 & 6.61 & 4.74 \\
\hline
\end{tabular}

B 429.1

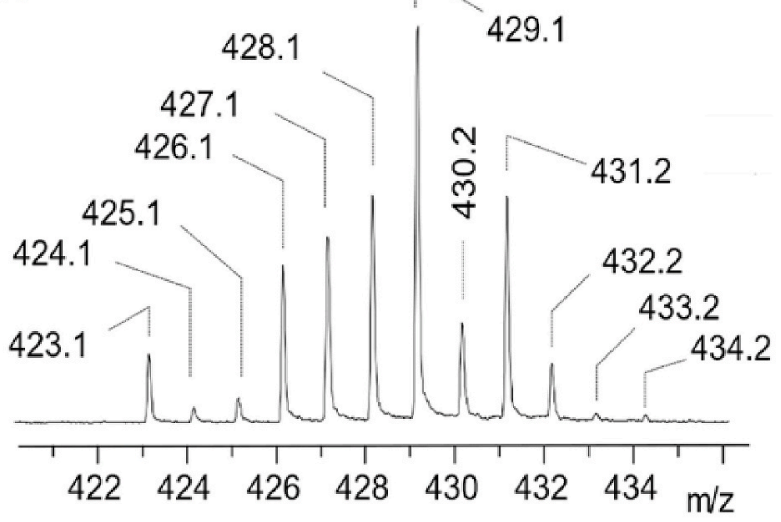

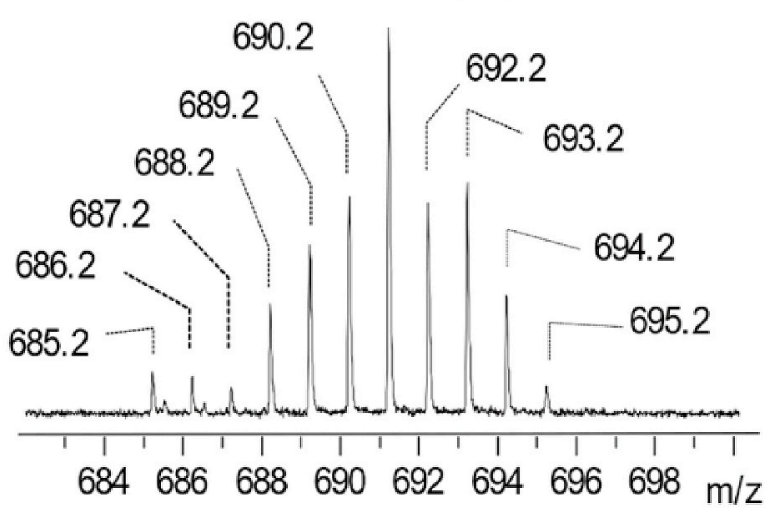

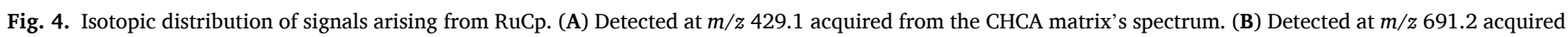
with the DHB matrix. 
are up to $20 \%$. The best reproducibility of the method (the smallest values of variations, Table 3, Table S3) were achieved for the RuCp in PBS ( $m / z$ 429.1) without matrix when within-day precision was calculated, and for the RuCp in urine $(\mathrm{m} / \mathrm{z} 429.1)$ without matrix when dayto-day repeatability was calculated. The values of variations for $\mathrm{S} / \mathrm{N}$ were $17.71 \%$ and $8.65 \%$, respectively, at the concentration of 78.125 $\mu \mathrm{M}$. For the lowest concentration in PBS the best within day repeatability was obtained with CHCA (24.77\%), and similar result was obtained for the highest statistically analysed concentration in urine $(22.72 \%)$ for the day-to-day repeatability. Other variations were rather high and not suitable for potential routine quantification of RuCp under physiological conditions. The differences in the RSD values at different concentrations indicate that for the applications in clinical laboratory, the patient's samples must be either concentrated or diluted to reach the concentration range that gives the best precision and repeatability.

Among the acquisition conditions, we have selected LDI as the most suitable for further improvements to meet the criteria for the future routine applications, i.e. for the enhancement of the sensitivity of RuCp detection in body fluids.

The overview of the statistical analysis is given in Fig. 5, in the box and whiskers plot, that confirms the findings presented above. Namely, the highest precision and the best reproducibility in PBS were obtained when the spectra are acquired with DHB and LDI mode, but on the other hand, the detectability was lower (lower S/N compared to CHCA). In urine, LDI and DHB gave similar results in terms of precision and reproducibility, although LDI showed a somewhat lower $\mathrm{S} / \mathrm{N}$ ratio (lower sensitivity) than DHB. In any case, the LDI approach can still be the choice for further studies, because, in this system, no additional signals are expected that could interfere with RuCp-derived signals, which could affect the reliability of the data obtained.

\subsection{Increasing the sensitivity of detection with $C D s$}

As indicated above, the advantage of the LDI approach is that no background signals of matrices are present in the spectra since it is well known that organic matrices complicate the spectra in the low mass range. On the other hand, it is known that the addition of nanoparticles, such as CDs, also to organic matrices [36], can increase the sensitivity of detection of various compounds. Using nanoparticles as substrates for MALDI-TOF MS detection can help to overcome the suppression of signals caused by the presence of inorganic salts [37]. Therefore, in the next part of our work, we wanted to test the detectability of RuCp in urine, in the LDI mode, upon the addition of CDs. The resulting spectra are given in Fig. S3, where it is evident that no additional signals are detectable in the spectra after the addition of CDs compared to the LDI mode. Homogeneity on the MALDI sample plate is presented in Fig. S4.

Table 3

The values of variations within-day precision and day-to-day repeatability for the signal parameters detected in the RuCp spectra acquired under different acquisition conditions. The concentration at which the ANOVA test is presented was $78.125 \mu \mathrm{M}$. An asterisk indicates acceptable values.

\begin{tabular}{|c|c|c|c|c|c|c|c|}
\hline & \multirow[t]{2}{*}{$m / \mathrm{z}$} & \multicolumn{3}{|c|}{$\begin{array}{l}\text { ANOVA } \\
\text { Day-to-day, \% }\end{array}$} & \multicolumn{3}{|c|}{$\begin{array}{l}\text { ANOVA } \\
\text { Within-Day, \% }\end{array}$} \\
\hline & & CHCA & DHB & LDI & CHCA & DHB & LDI \\
\hline $\begin{array}{l}\mathrm{S} / \mathrm{N} \text { in } \\
\mathrm{PBS}\end{array}$ & 429.1 & 82.34 & 90.09 & $17.71^{*}$ & 26.07 & 29.11 & 43.31 \\
\hline $\begin{array}{c}\text { Peak area } \\
\text { in PBS }\end{array}$ & 429.1 & 131.46 & 108.77 & $17.43^{*}$ & 59.15 & 41.84 & 38.52 \\
\hline $\begin{array}{l}\mathrm{S} / \mathrm{N} \text { in } \\
\mathrm{PBS}\end{array}$ & 691.2 & 135.82 & 104.82 & 42.54 & 53.44 & 60.02 & 66.12 \\
\hline $\begin{array}{c}\text { Peak area } \\
\text { in PBS }\end{array}$ & 691.2 & 143.44 & 112.14 & 29.67 & 69.81 & 63.60 & 55.99 \\
\hline $\begin{array}{l}\mathrm{S} / \mathrm{N} \text { in } \\
\text { urine }\end{array}$ & 429.1 & 106.73 & 44.40 & 70.62 & 143.53 & 25.33 & $8.65^{*}$ \\
\hline $\begin{array}{l}\text { Peak area } \\
\text { in urine }\end{array}$ & 429.1 & 106.42 & 51.4 & 58.24 & 128.39 & 28.27 & $15.30^{*}$ \\
\hline
\end{tabular}

Fig. 6 presents the response of the detector for the signal at $m / z 429.1$ detectable in urine spiked with various concentrations of RuCp given in $\mu \mathrm{M}$. The detector response is given in $\mathrm{S} / \mathrm{N}$ ratio, and the linearity equations are also presented in the figure. The sensitivity of detection is higher if urine is spiked with CDs compared to the LDI mode, but standard deviations are higher after the addition of CDs.

\subsection{Chemical model and interaction of RuCp with $C D s$}

To try to explain higher sensitivity of detection of RuCp in urine with the addition of CDs, we have performed numerical simulations and prepared the theoretical model for this interaction. It was possible thanks to the presence of only these components in urine, which are relevant for the desorption/ionization process. The potential energy surfaces on the $S_{0}$ state and the first ten excited singlet states that describe the formation of such a complex are represented in Fig. S5. They are obtained with the full linear interpolation method in internal coordinates [38-42].

Ionization potential and vertical excitation energies of the species studied in this work are given in Table S4. According to Fig. S5, all the represented states are bonding with respect to the formation of the complex. Furthermore, the optimization of the excited state, which matches with the irradiation wavelength, i.e., $S_{7}$ state (Table S4), ends at the geometry that it is only $2.98 \mathrm{eV}(\sim 415 \mathrm{~nm})$ above the $\mathrm{S}_{0}$ ground state surface. Consequently, dissociation of the $\mathrm{CpRu} / \mathrm{CDs}$ complex after irradiating at $355 \mathrm{~nm}$ must occur by relaxation of the system to an excited vibrational or continuous state of the $\mathrm{S}_{0}$ ground state. Concerning the ionization energy, the extracted electron arises from the $\mathrm{Ru}$ atom in all the cases. Higher ionization potential corresponds to the $\mathrm{RuCp} / \mathrm{CDs}$ system, whereas lower is assigned to both ions that arise from RuCp. Regarding the vertical excitation energy, it is worth emphasizing that the RuCp/CDs complex is the species, which has an absorption line close to the excitation source and with significant oscillatory strength. When discussing results obtained with other experimental systems, one must consider the ion stability and signals derived from matrices that can suppress the signal of interest, which all affect the detectability. Finally, these findings additionally emphasize the potential of the addition of the CDs nanoparticles to minimize the energy required for the desorption/ionization process.

The chemical structure selected as a model to simulate carbon quantum dots consists of substituted anthracene with the $(-\mathrm{COOH})$ group, in accordance with previous work on this type of system [43,44], this structure has been carefully simplified to avoid doubtful conclusions [45]. It is found that the most favourable interaction of RuCp with CDs takes place through the formation of a hydrogen bond between the $\mathrm{Cl}$ atom of RuCp and the hydroxyl moiety of the carboxylic substituent of the CDs (-O-H-Cl-). The minimum energy geometry of the RuCp/CDs complex is represented in Fig. S6. The enthalpy and Gibbs energy formation amount to 26.8 and $13.6 \mathrm{kcal} / \mathrm{mol}$, respectively. The developed model emphasizes the importance of the surface modifications and surface-based effects that could explain the mechanism of desorption and ionization, as well as the desired/targeted modifications of a nanoparticle that will result in better detectability of Ru-complexes potential metallodrugs.

\section{Conclusions}

In summary, we have presented and theoretically explained the potential of the MALDI-TOF MS-based method for the detection of the RuCp complex derivatives in human urine, a potential anti-tumour metallodrug. Besides the capacity for detection in urine, the detectability of this compound in PBS implies that this method can also be potentially used in other body fluids, as well. It is of high importance for ADME studies of drug candidates to apply an easy, fast, and sensitive method for the detection of either a drug or its metabolites in a physiological environment whenever possible. Since MALDI provides the 


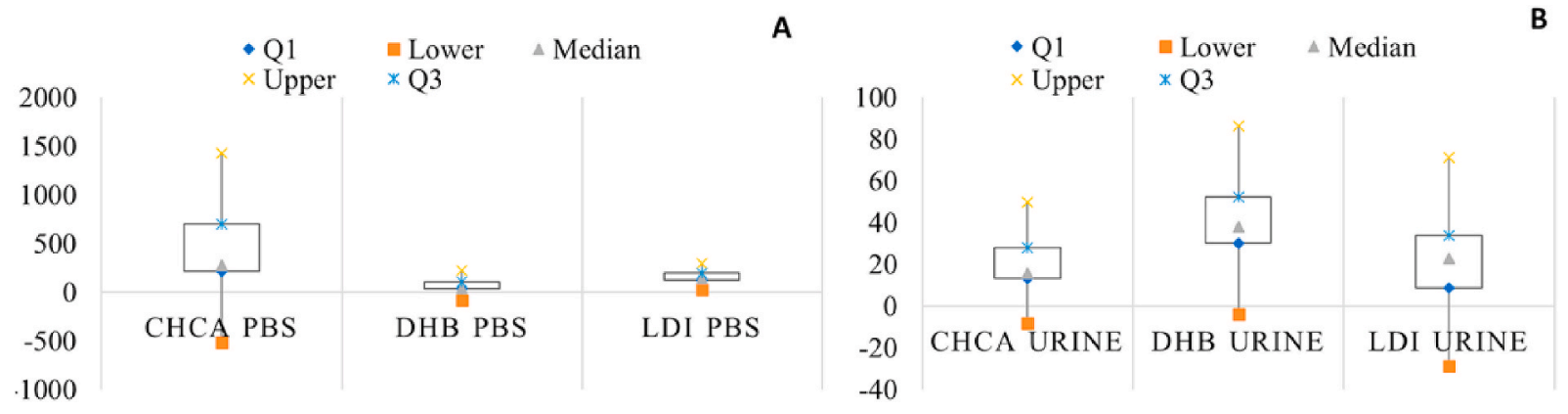

Fig. 5. Box and whiskers plot of the data obtained from the $\mathrm{S} / \mathrm{N}$ values for the signal at $m / z 429.1$ for $78.125 \mu \mathrm{M}$ of RuCp in (A) PBS and (B) urine.

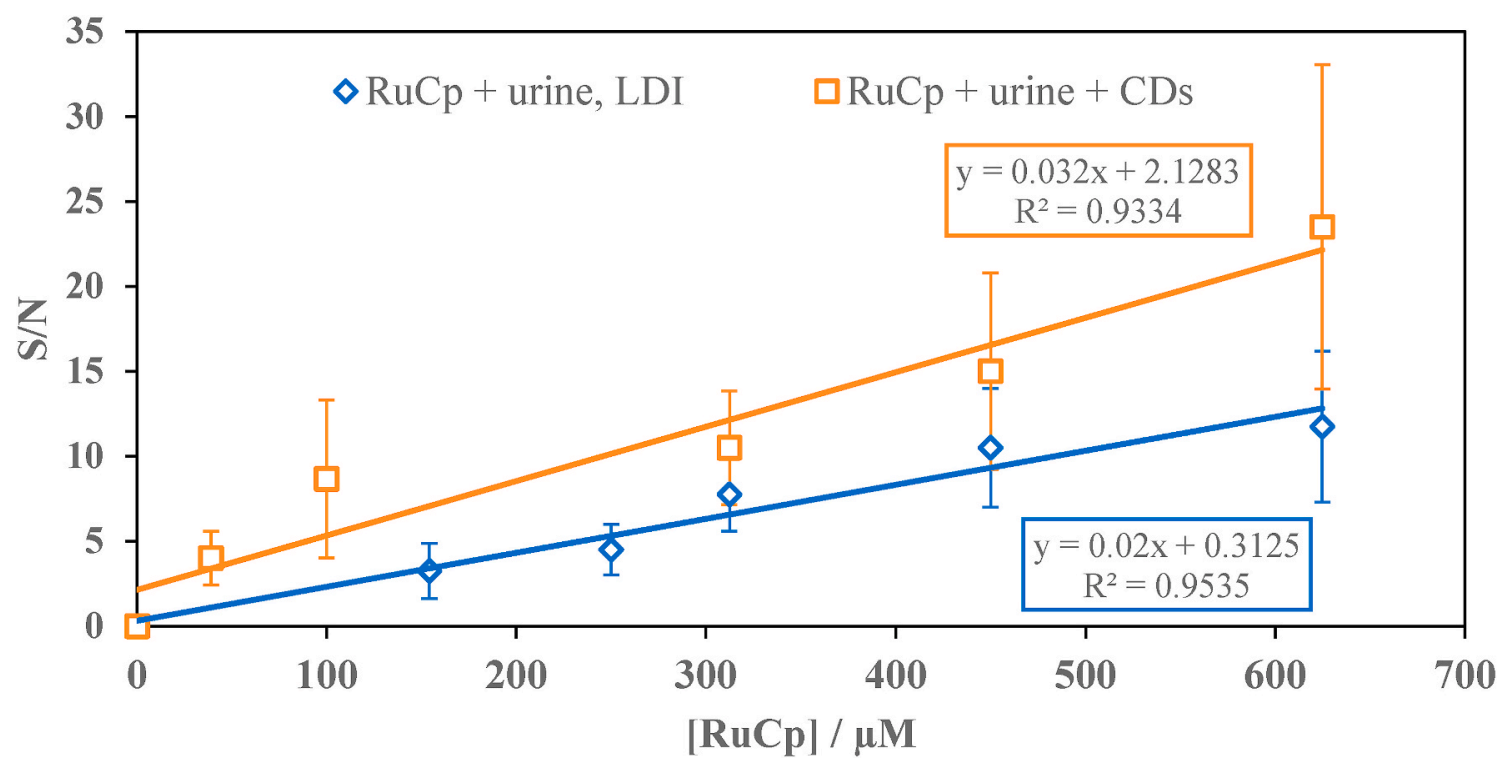

Fig. 6. Detectability of the RuCp complex in urine with and without CDs calculated based on the S/N ratio. Linearity equations are indicated in the graph.

opportunity to detect Ru-compounds without the isolation/purification from biological fluids, it is of high significance to set up and validate the method. From the results obtained in our study, we can conclude that CHCA as a matrix could be useful to overcome the drawbacks of inorganic phosphates that are abundant in some biological fluids. In contrast, in the human urine, DHB and the matrix-free approach gave the best precision and reproducibility, thus being more suitable for potential quantification. In addition to these outcomes, the application of the carbon-based nanoparticles (CDs) resulted in increased sensitivity for the detection of RuCp. Theoretical calculations of IP and vertical excitation energy near the emission wavelength of the laser supported the experimental data obtained and provided additional important parameters that can be crucial for the pre-selections of conditions for MALDI-TOF MS of RuCp and the future development of automated MS analysis in the clinical laboratory.

\section{Credit status statement}

N.N. main experimental part, data acquisition and discussion. I.P. data curation and manuscript writing. E.A. data curation and discussion. D.M. assistance in the RuCp synthesis and characterization. J.R. funding acquisition, writing review, and editing. J.S. DFT calculations and data interpretation. M.A. establishment of theoretical model, synthesis and characterization of CDs, writing review and editing. M.P. conceptualization, writing-original draft, and supervision of experiments, and editing.

\section{Declaration of competing interest}

The authors declare that they have no known competing financial interests or personal relationships that could have appeared to influence the work reported in this paper.

\section{Acknowledgments}

This work was supported by FCT-Fundação para a Ciência e a Tecnologia through the CQM Base Fund - UIDB/00674/2020, and Programmatic Fund - UIDP/00674/2020, and by the Ph.D. Grant SFRH/ BD/102123/2014 (DM). The Madeira 14-20 Program and ARDITIAgência Regional para o Desenvolvimento da Investigação Tecnologia e Inovação, respectively through the projects PROEQUIPRAM - Reforço do Investimento em Equipamentos e Infraestruturas Científicas na RAM (M1420-01-0145-FEDER-000008), M1420-01-0145-FEDER-000005 Centro de Química da Madeira - CQM+ and ARDITI-CQM/2017/013MDG (Fellowship Grant to NN) are also acknowledged for the support provided. This work has been also supported by the Spanish Ministerio de Economía, Industria y Competividad (CTQ2015-65816-R and RTI2018-099668-BC22), project UMA18-FEDERJA-126 of Junta de Andalucía and FEDER founds. (UMA18-FEDERJA-049 and P18-RT4592). JS thanks Rafael Larrosa and Darío Guerrero for the technical support in running the calculations and the SCBI (Supercomputer and Bioinformatics) of the Univ. Málaga for computer and software resources. 


\section{Appendix A. Supplementary data}

Supplementary data to this article can be found online at https://doi. org/10.1016/j.talanta.2020.121551.

\section{References}

[1] S.M. Bagshaw, C. Langenberg, R. Bellomo, Urinary biochemistry and microscopy in septic acute renal failure: a systematic review, Am. J. Kidney Dis. 48 (2006) 695-705, https://doi.org/10.1053/j.ajkd.2006.07.017.

[2] C. Lima, E. Macedo, Urinary biochemistry in the diagnosis of acute kidney injury, dis, Markers 2018 (2018) 1-7, https://doi.org/10.1155/2018/4907024.

[3] N. Penner, L. Xu, C. Prakash, Radiolabeled absorption, distribution, metabolism, and excretion studies in drug development: why, when, and how? Chem. Res. Toxicol. 25 (2012) 513-531, https://doi.org/10.1021/tx300050f.

[4] S. Dasari, P. Bernard Tchounwou, Cisplatin in cancer therapy: molecular mechanisms of action, Eur. J. Pharmacol. 740 (2014) 364-378, https://doi.org/ 10.1016/j.ejphar.2014.07.025.

[5] J. Hrabeta, V. Adam, T. Eckschlager, E. Frei, M. Stiborova, R. Kizek, Metal Containing Cytostatics, Their Interaction, With cellular thiol compounds causing chemoresistance, Anticancer Agents Med. Chem. 16 (2016) 686-698, https://doi.org/10.2174/1871520616666151120122611.

[6] L. Zeng, P. Gupta, Y. Chen, E. Wang, L. Ji, H. Chao, Z.-S. Chen, The development of anticancer ruthenium( ii ) complexes: from single molecule compounds to nanomaterials,, Chem. Soc. Rev. 46 (2017) 5771-5804, https://doi.org/10.1039/ C7CS00195A.

[7] I. Ott, R. Gust, Non platinum metal complexes as anti-cancer drugs, Arch. Pharm. (Weinheim) 340 (2007) 117-126, https://doi.org/10.1002/ardp.200600151.

[8] L. Zeng, Y. Chen, J. Liu, H. Huang, R. Guan, L. Ji, H. Chao, Ruthenium(II) complexes with 2-Phenylimidazo[4,5-f][1,10]phenanthroline derivatives that strongly combat cisplatin-resistant tumor cells, Sci. Rep 6 (2016) 19449, https:// doi.org/10.1038/srep19449.

[9] S. Leijen, S.A. Burgers, P. Baas, D. Pluim, M. Tibben, E. van Werkhoven, E. Alessio, G. Sava, J.H. Beijnen, J.H.M. Schellens, Phase I/II study with ruthenium compound NAMI-A and gemcitabine in patients with non-small cell lung cancer after first line therapy, Invest, N. Drugs 33 (2015) 201-214, https://doi.org/10.1007/s10637014-0179-1.

[10] J.M. Rademaker-Lakhai, I. A Phase, Pharmacological Study, With imidazoliumtrans-DMSO-imidazole-tetrachlororuthenate, a novel ruthenium anticancer agent, Clin. Canc. Res. 10 (2004) 3717-3727, https://doi.org/10.1158/1078-0432.CCR03-0746.

[11] C.G. Hartinger, S. Zorbas-Seifried, M.A. Jakupec, B. Kynast, H. Zorbas, B. K. Keppler, From bench to bedside - preclinical and early clinical development of the anticancer agent indazolium trans-[tetrachlorobis $(1 \mathrm{H}$-indazole)ruthenate(III)] (KP1019 or FFC14A), J. Inorg. Biochem. 100 (2006) 891-904, https://doi.org/ 10.1016/j.jinorgbio.2006.02.013.

[12] K. Lin, Z.-Z. Zhao, H.-B. Bo, X.-J. Hao, J.-Q. Wang, Applications of ruthenium complex in tumor diagnosis and therapy, Front. Pharmacol. 9 (2018) 1323, https://doi.org/10.3389/fphar.2018.01323.

[13] C. Riccardi, D. Musumeci, M. Trifuoggi, C. Irace, L. Paduano, D. Montesarchio, Anticancer ruthenium(III) complexes and Ru(III)-Containing nanoformulations: an update on the mechanism of action and biological activity, Pharmaceuticals 12 (2019) 146, https://doi.org/10.3390/ph12040146.

[14] M. Frik, A. Martínez, B.T. Elie, O. Gonzalo, D. Ramírez de Mingo, M. Sanaú, R. Sánchez-Delgado, T. Sadhukha, S. Prabha, J.W. Ramos, I. Marzo, M. Contel, In Vitro and in vivo evaluation of water-soluble iminophosphorane ruthenium(II) compounds. A potential chemotherapeutic agent for triple negative breast cancer, J. Med. Chem. 57 (2014) 9995-10012, https://doi.org/10.1021/jm5012337.

[15] L. Kersten, H. Bräunlich, B.K. Keppler, C. Gliesing, M. Wendelin, J. Westphal, Comparative nephrotoxicity of some antitumour-active platinum and ruthenium complexes in rats, J. Appl. Toxicol. JAT 18 (1998) 93-101, https://doi.org/ 10.1002/(sici)1099-1263(199803/04)18:2<93::aid-jat472>3.0.co;2-w.

[16] F. Lentz, A. Drescher, A. Lindauer, M. Henke, R.A. Hilger, C.G. Hartinger, M. E. Scheulen, C. Dittrich, B.K. Keppler, U. Jaehde, Pharmacokinetics of a novel anticancer ruthenium complex (KP1019, FFC14A) in a phase I dose-escalation study, Anti Canc. Drugs 20 (2009) 97-103, https://doi.org/10.1097/ CAD.0b013e328322fbc5.

[17] G.J. Yoshida, Applications of patient-derived tumor xenograft models and tumor organoids, J. Hematol. Oncol. 13 (2020) 4, https://doi.org/10.1186/s13045-019 0829-z.

[18] Q. Cheng, Y. Cui, N. Xiao, J. Lu, C.-J. Fang, Synthesis of a novel fluorescent ruthenium complex with an appended Ac4GlcNAc moiety by click reaction, Molecules 23 (2018) 1649, https://doi.org/10.3390/molecules23071649.

[19] P. Heffeter, K. Böck, B. Atil, M.A. Reza Hoda, W. Körner, C. Bartel, U. Jungwirth, B. K. Keppler, M. Micksche, W. Berger, G. Koellensperger, Intracellular protein binding patterns of the anticancer ruthenium drugs KP1019 and KP1339, JBIC J, Biol. Inorg. Chem. 15 (2010) 737-748, https://doi.org/10.1007/s00775-010 0642-1.

[20] F. Hillenkamp, J. Peter-Katalini (Eds.), MALDI MS, Wiley-VCH Verlag GmbH \& Co, KGaA, Weinheim, Germany, 2007, https://doi.org/10.1002/9783527610464.

[21] B. Damnjanović, T. Kamčeva, B. Petrović, Ž.D. Bugarčić, M. Petković, Laser desorption and ionization time-of-flightversus matrix-assisted laser desorption and ionization time-of-flight mass spectrometry of $\mathrm{Pt}(\mathrm{ii})$ and $\mathrm{Ru}$ ( iii ) metal complexes, Anal Methods 3 (2011) 400-407, https://doi.org/10.1039/C0AY00517G.
[22] M. Petković, A. Vujačić, J. Schiller, Ž. Bugarčić, J. Savić, V. Vasić, Application of flavonoids - quercetin and rutin - as new matrices for matrix-assisted laser desorption/ionization time-of-flight mass spectrometric analysis of $\mathrm{Pt}(\mathrm{II})$ and $\mathrm{Pd}(\mathrm{II})$ complexes, Rapid Commun, Mass Spectrom. 23 (2009) 1467-1475, https://doi. org $/ 10.1002 / \mathrm{rcm} .4024$.

[23] I.A. Popović, M. Nešić, M. Vranješ, Z. Šaponjić, M. Petković, SALDI-TOF-MS analyses of small molecules (citric acid, dexasone, vitamins E and A) using TiO2 nanocrystals as substrates, Anal. Bioanal. Chem. 408 (2016) 7481-7490, https:// doi.org/10.1007/s00216-016-9846-8.

[24] M. Gouveia, J. Figueira, M. Jardim, R. Castro, H. Tomás, K. Rissanen, J. Rodrigues, Poly(alkylidenimine) dendrimers functionalized with the organometallic moiety [Ru(n5-C5H5)(PPh3)2] + as promising drugs against cisplatin-resistant cancer cells and human mesenchymal stem cells, Molecules 23 (2018) 1471, https://doi.org/ 10.3390/molecules23061471.

[25] K.-J. Rhee, J. Lee, Y. Eom, Mesenchymal stem cell-mediated effects of tumor support or suppression, Int. J. Mol. Sci. 16 (2015) 30015-30033, https://doi.org/ $10.3390 /$ ijms161226215.

[26] M.I. Bruce, C. Hameister, A.G. Swincer, R.C. Wallis, S.D. Ittel, Chloro ( $\eta^{5}-$ Cyclopentadienyl)Bis(triphenyl-phosphine) ruthenium(II): $\operatorname{rucl}\left(\mathrm{PPh}_{3}\right)_{2}\left(\eta^{5}-\mathrm{C}_{5} \mathrm{H}_{5}\right)$, in: R.J. Angelici (Ed.), Inorg. Synth., John Wiley \& Sons, Inc., USA, Hoboken, NJ, 2007, pp. 270-272, https://doi.org/10.1002/9780470132593.ch69.

[27] M. Algarra, B.B. Campos, K. Radotić, D. Mutavdžić, T. Bandosz, J. JiménezJiménez, E. Rodriguez-Castellón, J.C.G. Esteves da Silva, Luminescent carbon nanoparticles: effects of chemical functionalization, and evaluation of $\mathrm{Ag}+$ sensing properties, J. Mater. Chem. A 2 (2014) 8342, https://doi.org/10.1039/ c4ta00264d.

[28] Y. Zhao, N.E. Schultz, D.G. Truhlar, Design of density functionals by combining the method of constraint satisfaction with parametrization for thermochemistry, thermochemical kinetics, and noncovalent interactions, J. Chem. Theor. Comput. 2 (2006) 364-382, https://doi.org/10.1021/ct0502763.

[29] S. Grimme, J. Antony, S. Ehrlich, H. Krieg, A consistent and accurate ab initio parametrization of density functional dispersion correction (DFT-D) for the 94 elements H-Pu, J. Chem. Phys. 132 (2010), 154104, https://doi.org/10.1063/ 1.3382344.

[30] L. Goerigk, A. Hansen, C. Bauer, S. Ehrlich, A. Najibi, S. Grimme, A look at the density functional theory zoo with the advanced GMTKN55 database for general main group thermochemistry, kinetics and noncovalent interactions, Phys. Chem. Chem. Phys. 19 (2017) 32184-32215, https://doi.org/10.1039/C7CP04913G.

[31] F. Weigend, Accurate coulomb-fitting basis sets for $\mathrm{H}$ to Rn, Phys. Chem. Chem. Phys. 8 (2006) 1057, https://doi.org/10.1039/b515623h.

[32] F. Weigend, R. Ahlrichs, Balanced basis sets of split valence, triple zeta valence and quadruple zeta valence quality for $\mathrm{H}$ to $\mathrm{Rn}$ : design and assessment of accuracy, Phys. Chem. Chem. Phys, 73297 (2005), https://doi.org/10.1039/b508541a.

[33] Gaussian 09, Revision C.01 M.J. Frisch, G.W. Trucks, H.B. Schlegel, G.E. Scuseria, M.A. Robb, J.R. Cheeseman, G. Scalmani, V. Barone, B. Mennucci, G.A. Petersson, H. Nakatsuji, M. Caricato, X. Li, H.P. Hratchian, A.F. Izmaylov, J. Bloino, G. Zheng, J.L. Sonnenberg, M. Hada, M. Ehara, K. Toyota, R. Fukuda, J. Hasegawa, M. Ishida, T. Nakajima, Y. Honda, O. Kitao, H. Nakai, T. Vreven, J.A. Montgomery Jr., J. E. Peralta, F. Ogliaro, M. Bearpark, J.J. Heyd, E. Brothers, K.N. Kudin, V. N. Staroverov, R. Kobayashi, J. Normand, K. Raghavachari, A. Rendell, J.C. Burant, S.S. Iyengar, J. Tomasi, M. Cossi, N. Rega, N.J. Millam, M. Klene, J.E. Knox, J. B. Cross, V. Bakken, C. Adamo, J. Jaramillo, R. Gomperts, R.E. Stratmann, O. Yazyev, A.J. Austin, R. Cammi, C. Pomelli, J.W. Ochterski, R.L. Martin, K. Morokuma, V.G. Zakrzewski, G.A. Voth, P. Salvador, J.J. Dannenberg, S. Dapprich, A.D. Daniels, Ö. Farkas, J.B. Foresman, J.V. Ortiz, J. Cioslowski, D. J. Fox, Gaussian 16, Revision A.03, Gaussian Inc., Wallingford CT, 2016.

[34] J. Soto, E. Imbarack, I. López-Tocón, S. Sánchez-Cortés, J.C. Otero, P. Leyton, Application of surface-enhanced resonance Raman scattering (SERS) to the study of organic functional materials: electronic structure and charge transfer properties of 9,10-bis(( E )-2-(pyridin-4-yl)vinyl)anthracene, RSC Adv. 9 (2019) 14511-14519, https://doi.org/10.1039/C9RA01269A.

[35] I. Popović, M. Nešić, M. Nišavić, M. Vranješ, T. Radetić, Z. Šaponjić, R. Masnikosa, M. Petković, Suitability of TiO2 nanoparticles and prolate nanospheroids for laser desorption/ionization mass spectrometric characterization of bipyridinecontaining complexes, Mater. Lett. 150 (2015) 84-88, https://doi.org/10.1016/j. matlet.2015.03.004.

[36] Y. Chen, D. Gao, H. Bai, H. Liu, S. Lin, Y. Jiang, Carbon dots and 9AA as a binary matrix for the detection of small molecules by matrix-assisted laser desorption/ ionization mass spectrometry, J. Am. Soc. Mass Spectrom. 27 (2016) 1227-1235, https://doi.org/10.1007/s13361-016-1396-y.

[37] M. Radisavljević, T. Kamčeva, I. Vukićević, M. Radoičić, Z. Šaponjić, M. Petković, Colloidal $\mathrm{TiO}_{2}$ nanoparticles as substrates for M(S)ALDI mass spectrometry of transition metal complexes: colloidal $\mathrm{TiO}_{2}$ nanoparticles as substrates for $\mathrm{M}(\mathrm{S})$ ALDI MS, Rapid Commun, Mass Spectrom. 26 (2012) 2041-2050, https://doi.org/ 10.1002/rcm.6320.

[38] J. Soto, M. Algarra, Insights into the thermal and photochemical reaction mechanisms of azidoacetonitrile. Spectroscopic and MS-CASPT2 calculations, ChemPhysChem (2020), https://doi.org/10.1002/cphc.202000201.

[39] D. Peláez, J.F. Arenas, J.C. Otero, J. Soto, Dependence of $N$-Nitrosodimethylamine photodecomposition on the irradiation wavelength: excitation to the $\mathrm{S}_{2}$ state as a doorway to the dimethylamine radical ground-state chemistry, J. Org. Chem. 72 (2007) 4741-4749, https://doi.org/10.1021/jo070399a.

[40] J. Soto, D. Peláez, J.C. Otero, F.J. Avila, J.F. Arenas, Photodissociation mechanism of methyl nitrate. A study with the multistate second-order multiconfigurational perturbation theory, Phys. Chem. Chem. Phys 11 (2009) 2631, https://doi.org/ 10.1039/b820646e. 
[41] D. Peláez, J.F. Arenas, J.C. Otero, J. Soto, A complete active space self-consistent field study of the photochemistry of nitrosamine, J. Chem. Phys 125 (2006), 164311, https://doi.org/10.1063/1.2360259.

[42] D. Aranda, F.J. Avila, I. López-Tocón, J.F. Arenas, J.C. Otero, J. Soto, An MSCASPT2 study of the photodecomposition of 4-methoxyphenyl azide: role of internal conversion and intersystem crossing, Phys. Chem. Chem. Phys. 20 (2018) 7764-7771, https://doi.org/10.1039/C8CP00147B.

[43] M. Algarra, V. Moreno, J.M. Lázaro-Martínez, E. Rodríguez-Castellón, J. Soto, J. Morales, A. Benítez, Insights into the formation of $\mathrm{N}$ doped 3D-graphene quantum dots. Spectroscopic and computational approach, J. Colloid Interface Sci. 561 (2020) 678-686, https://doi.org/10.1016/j.jcis.2019.11.044.

[44] J. Soto, J.M. Rosas, J.C. Otero, J. Rodríguez-Mirasol, T. Cordero, Reaction mechanisms of 2-butanol dehydration over a phosphorus-containing activated carbon acid catalyst, J. Phys. Chem. C 122 (2018) 16772-16778, https://doi.org/ 10.1021/acs.jpcc.8b03700.

[45] A. Fernández-Ramos, J. Rodríguez-Otero, M.A. Ríos, J. Soto, Intramolecular proton transfer in 2-(2'-hydroxyphenyl)benzoxazole: the reliability of ab initio calculations on simplified structures, J. Mol. Struct. THEOCHEM 489 (1999) 255-262, https://doi.org/10.1016/S0166-1280(99)00062-7. 